\title{
The Effect of Low Level Laser Therapy on Pemphigus Vulgaris Lesions: A Pilot Study
}

\author{
Maryam Yousefi ${ }^{1}$, Parvin Mansouri ${ }^{2}$, Masoud Partovikia ${ }^{1}$, Mitra Esmaili', Shima Younespour ${ }^{1}$, Ladan Hassani ${ }^{1 *}$ \\ 'Skin Research Center, Shahid Beheshti University of Medical Sciences, Tehran, Iran \\ ${ }^{2}$ Skin and Stem Cell Research Center, Tehran University of Medical Sciences, Tehran, Iran
}

\section{*Correspondence to}

Ladan Hassani, MD; Skin Research

Center, Shahid Beheshti University

of Medical Sciences, Tehran, Iran

Tel: +98 2122744393;

Fax: +98 2122744393

Email: ladanhassani@yahoo.com

Published online 27 September 2017

\begin{abstract}
Introduction: Pemphigus vulgaris is a chronic blistering skin disease. Management of recalcitrant pemphigus ulcers is a great problem. Low Level Laser Therapy (LLLT) is known to supply direct biostimulative light energy to body cells. This study evaluates the efficacy of low power laser in the healing of pemphigus lesions.

Methods: Ten patients with pemphigus vulgaris were enrolled in the trial. The LED-LLLT system used was the Thor LED clusters (109, 69 or 19 diode) (England) with $660 \mathrm{~nm}$ wavelength in continuous wave $(\mathrm{CW})$ and $30 \mathrm{~mW}$ energy. Both sides of the patients' lesion were photographed prior to the study and in each laser therapy session.

Results: The pattern of changes in qualitative wound score (QWS) patterns differed significantly over time between the two therapies (treatment $\times$ time interactions, $P<0.0001$ ). When compared to the routine therapy, the laser therapy showed more decrease in mean QWS in all sessions in comparison with baseline.

Conclusion: Application of low level laser simultaneously with conventional therapy could result in sensational healing of ulcers especially in patients who do not respond to conventional treatment or suffering from recalcitrant lesions.

Keywords: Pemphigus vulgaris; Laser therapy; Low-level; lesion; Wound healing.
\end{abstract}

\section{Introduction}

Pemphigus vulgaris is a chronic blistering skin disease in which autoantibodies are directed against the cell surface of keratinocytes. The majority of patients with pemphigus vulgaris develop the disease spontaneously. Systemic steroid plus steroid sparing agent's therapy is still the mainstay of treatment for the disease. However, these treatment modalities have various adverse effects. ${ }^{1}$ Amongst which is some patients do not respond to these treatments. Management of recalcitrant pemphigus ulcers is therefore a great problem.

Various laser devices such as carbon dioxide laser has been used to treat recalcitrant pemphigus lesions. ${ }^{2,3}$ Low level laser therapy (LLLT) is known to supply direct biostimulative light energy to body cells. The absorbed laser energy does not cause rapid or significant increase in tissue temperature. ${ }^{4}$ Low-energy laser radiation has been found to have a stimulating effect on cells and its application in stimulating wound healing in cases of nonhealing lesions has been recommended., 5 There are few reports on ulcers due to pemphigus vulgaris in literature, ${ }^{7}$ thus, the aim of this study is the evaluation of the efficacy of low power laser in the treatment of pemphigus lesions.

\begin{abstract}
Methods
Ten patients with pemphigus vulgaris were enrolled in the trial. Participants' age were more than 18 years; and all provided written informed consent for inclusion in the study. Pemphigus vulgaris diagnosis was made by a specified dermatologist and confirmed by histopathology and direct immunofluorescence evaluation. Patients for this study were recruited from Shohada-e Tajrish hospital of Shahid Beheshti University of Medical Sciences, Tehran, Iran.

The criteria for inclusion in the study included had a minimum of 2 ulcers or erosions, the patient underwent the minimum one-month treatment for pemphigus (prednisolone $2 \mathrm{mg} / \mathrm{kg} / \mathrm{d}$ and azathioprine $2 \mathrm{mg} / \mathrm{kg} / \mathrm{d}$ ) and did not respond, satisfaction of the patient or his/her family to participate in the study and non-existence of photosensitivity. The criteria for exclusion from the study included sores on joints in children due to an opening in the growth plate, skin sores close to the thyroid gland, facial sores near the eye and infectious sores.

The body (head, scalp, chest wall, abdomen and back) of each patient was divided into two equal parts: right and left sides. The patients underwent laser and routine
\end{abstract}


treatments simultaneously on one side of their body while the other side did not receive any treatment. The LED-LLLT system used was the Thor LED clusters (109, 69 or 19 diode) (England) with $660 \mathrm{~nm}$ wavelength in continuous wave (CW) and $30 \mathrm{MW}$ energy. Number of laser therapy sessions was 3 sessions per week for 2 weeks. The recommended distance between laser head and target tissue was 10 to $17 \mathrm{~cm}$, within which the near-field irradiance remains virtually identical.

Lesions on both sides of the patients were photographed prior to the study and in each laser therapy sessions. The photos were reviewed and graded ( 0 to 10 ) by 2 dermatologists. Grading was performed on the basis of visual analogue scale (VAS) as follows:

(1) sore recovery quantity with $100 \mathrm{~mm}$ VAS is evaluated: 0 as non-recovery and 100 as full recoveries is considered. However, for the purpose of analyses, the scale was thus: 0 to 24 as non-recovery or slight recovery; 25 to 49 as average recovery; 50-74 as considerable recovery; 75-100 as Full recovery.

(2) Sore grading or qualitative wound score (QWS), with the following total grades as: 0: the best result and 7: the worst result.

Red severity: $0=$ Not, $1=$ pink, $2=$ red

Exudate quantity: $0=$ Not, $1=$ less, $2=$ average to severe

Odor: $0=$ not having, $1=$ having

Sore size: $0=$ lower, 1 = same rate, 2 = larger

After the time period for the study elapsed, the patients were followed up for 2 months (2, 4 and 8 weeks) after treatment.

Patient satisfaction rate from treatment was evaluated as without change, good, average, excellent and very excellent.

In this study, PAAS pointing system (Pemphigus Area and Activity Score) was used for severe and progressive clinical evaluation of pemphigus vulgaris. ${ }^{8}$

\section{Statistical Methods}

Continuous variables are presented as mean (SD) or as medians with a total and interquartile range of 25th-75th percentiles. Categorical data are reported in numbers. The normality of continuous variables was examined by Shapiro-Wilk W-test. The Friedman test and Wilcoxon signed-rank test were applied for data analyses.

Generalized estimating equation (GEE) models were applied to examine the associations between type of therapy (laser therapy and routine therapy) and change in QWS values over time of study. GEE models included two main effects (type of therapy and time) and the interaction of these effects.

The statistical software SPSS 16.0.0 (SPSS Inc., Chicago, IL, USA) was used for all data analyses. $P$ values less than 0.05 were considered statistically significant.

\section{Results}

Ten patients with pemphigus vulgaris (4 female and 6 male) were used in this study. The mean (SD) age of the patients was 43.20 (14.49) years (range: 18 to 64 years). The median duration of the disease was 1 year (range: 2 weeks to 25 years). Table 1 shows the summary of QWS values in patients with pemphigus vulgaris during the study period.

The patterns of change in QWS differed significantly over time between the 2 therapies (treatment $\times$ time interactions, $P<0.0001)$. Mean QWS decreased significantly during the study period in both treatments. When compared to routine therapy, laser therapy showed more decreases in mean QWS in all sessions in comparison with baseline.

When compared to the routine therapy, laser therapy showed an additional 3.20 decrease in mean QWS of patients during the first week of study $(P<0.0001)$. Also, the laser treatment compared to the routine treatment showed an additional 1.30 points decrease in mean QWS from baseline until week $2(P<0.0001)$. Compared to the routine therapy, laser therapy had a greater reduction in the mean QWS from baseline to week 8 after treatment (mean difference 0.5 points, $P=0.02$ ). The result of patients' satisfaction is summarized in Table 2. The pattern of change in VAS scores through the course of the study is shown in Figure 1. The VAS scores were significantly increased (both $P<0.0001$ and Friedman test) in both treatments through the course of the study. After 1 week of treatment, the sores treated with laser were significantly more improved in comparison with the routine therapy $(P=0.002)$.

\section{Discussion}

Pemphigus is a group of relatively rare, chronic autoimmune disorders characterized by formation of intraepithelial bullae in the skin and mucous membrane. ${ }^{1}$ Systemic steroids remain the main treatment for pemphigus as they induce rapid remissions. However, the adverse effects of steroids are time and dose dependent. Adjuvant therapies are therefore used to provide a steroidsparing effect but these medications are often associated with significant toxicities.

Wound healing and tissue repair are complex processes that involve dynamic series of events including

Table 1. Summary of QWS Values in Patients With Pemphigus Vulgaris at Baseline, Weeks 1 and 2 and 2, 4 and 8 Weeks After Treatment

\begin{tabular}{lll}
\hline & Laser & Routine Treatment \\
\hline Baseline & $5(4-5.25) ;(4-6)$ & $4.5(4-5.25) ;(3-6)$ \\
Week 1 & $1(0-2) ;(0-3)$ & $4.5(2.75-5.25) ;(2-6)$ \\
Week 2 & $1(0-1) ;(0-2)$ & $2(1-2.25) ;(0-3)$ \\
Two weeks after treatment & $0(0-1) ;(0-3)$ & $1.5(0.75-2) ;(0-3)$ \\
Four weeks after treatment & $0(0-0) ;(0-1)$ & $1(0-1.25) ;(0-3)$ \\
Eight weeks after treatment & $0(0-0) ;(0-1)$ & $0(0-1) ;(0-2)$ \\
\hline
\end{tabular}

Abbreviation: QWS, qualitative wound score.

The values are expressed as median (25th -75 th percentiles); (min-max). 
Table 2. The Results of Patients' Satisfaction

\begin{tabular}{|c|c|c|c|c|c|}
\hline & Without Change & Moderate & Good & Excellent & Very Excellent \\
\hline \multicolumn{6}{|l|}{ Routine therapy } \\
\hline Week 1 & 6 & 4 & 0 & 0 & 0 \\
\hline Week 2 & 0 & 7 & 3 & 0 & 0 \\
\hline Two weeks after treatment & 0 & 3 & 1 & 6 & 0 \\
\hline Four weeks after treatment & 0 & 1 & 1 & 8 & 0 \\
\hline Eight weeks after treatment & 0 & 1 & 0 & 5 & 4 \\
\hline \multicolumn{6}{|l|}{ Laser therapy } \\
\hline Week 1 & 0 & 1 & 0 & 7 & 2 \\
\hline Week 2 & 0 & 1 & 0 & 2 & 7 \\
\hline Two weeks after treatment & 0 & 0 & 0 & 1 & 9 \\
\hline Four weeks after treatment & 0 & 0 & 0 & 1 & 9 \\
\hline Eight weeks after treatment & 0 & 0 & 0 & 1 & 9 \\
\hline
\end{tabular}

The values are number of participants.

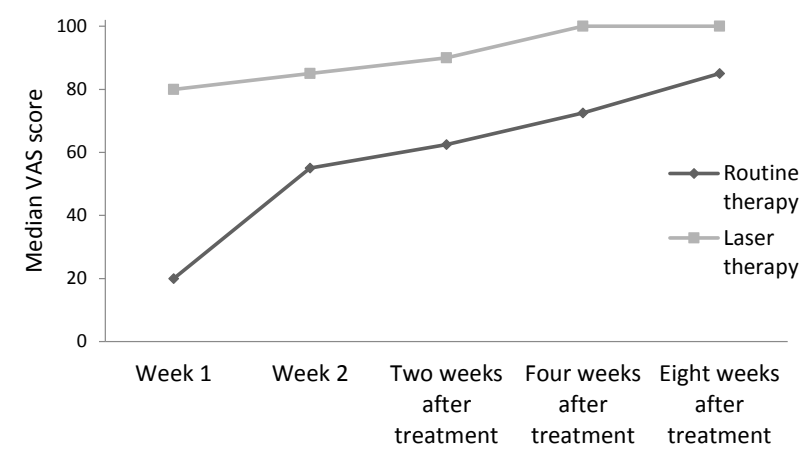

Figure 1. The Results of Patients' Satisfaction.

clotting, inflammation, granulation tissue formation, epithelialization, collagen synthesis and tissue remodeling. ${ }^{9}$ There is a wide array of studies on the effect of laser therapy such as carbon dioxide laser on wound healing in comparison to previous methods and this affects assessment grossly and histopathologically. ${ }^{3}$ It is also claimed that LLLT can lead to increased mitochondrial activity with a consequent increase in adenosine triphosphate (ATP), vasodilation, protein synthesis, decrease in prostaglandin levels, presence of cellular mitosis, migration and proliferation of keratinocytes and neoangiogenesis. ${ }^{10-13}$ Biometrical and histological analyses indicated faster lesion contraction showing quicker reepithelization and reformed connective tissue with more organized collagen fibers in irradiated wounds. ${ }^{14}$ Laser therapy reduces inflammatory reaction and provokes a greater proliferation of myofibroblasts in experimental cutaneous wounds. ${ }^{15,16}$ LLLT is a nondestructive, non-thermal and painless procedure with no thermal damage effects. LLLT has biostimulatory effects on surrounding tissues and cells, and an increase in systemic microcirculation and tissue oxygenation, cell metabolism and tissue regeneration and potential tissue healing. ${ }^{6}$

There are some studies that have shown that LLLT is effective in burn scar healing ${ }^{17}$ and superficial wound healing. Gal et al showed that LLLT at $670 \mathrm{~nm}$ positively influenced all phases of rat skin wound healing by studying both irradiated and control wounds. ${ }^{18}$ Lucas et al concluded that there are no scientific arguments for routine application of low level (infrared) laser therapy on wound healing in patients with decubitus ulcers, venous leg ulcers or other chronic wounds. ${ }^{19}$ Posten et al criticized other studies assessing the qualitative and quantitative sufficiency of evidence for the efficacy of LLLT in promoting wound healing in humans as the majority of studies did not demonstrate any benefit. ${ }^{20}$ A review from 2008 by Sobanko and Alster discussed 12 randomized controlled trials of chronic cutaneous ulceration with a focus on venous leg ulcers and decubitus ulcers. They concluded that LLLT in humans does not improve wound healing. ${ }^{21}$ Shindle et al $^{22}$ mentioned that the effect of LLLT has been shown to be different in certain etiologies of ulcers, therefore a sophisticated evaluation of the properties of LLLT in different diseases is mandatory. LLLT has been introduced as a new treatment option for patients with PV lesions unresponsive to conventional therapy. Pavlic et $\mathrm{al}^{23}$ in a review article evaluating the available literature on the effects of LLLT in the treatment of pemphigus concluded that LLLT is efficient in the treatment of recalcitrant oral pemphigus lesions, either used alone $e^{3,24}$ or as an adjunct to conventional treatment modalities.?

The present study aimed at evaluating the effects of LLLT in the treatment of recalcitrant pemphigus lesions. Our study showed that LLLT is efficient in the treatment of recalcitrant cutaneous pemphigus ulcers. The results of this study are in agreement with Minicucci et $\mathrm{al}^{7}$ who reported that LLLT was good for wound healing in pemphigus patients. They reported two cases of 
pemphigus in which LLLT induced faster healing in oral and cutaneous lesions.

Since this is a pilot study with a small sample size, it is suggested that further research be carried out. In order to determine the real efficacy of laser therapy (the optimal set of laser irradiation parameters and well-defined duration and frequency of intervals), further carefully designed long-term clinical studies with a larger sample size (possibly international) are necessary as well as prolonged follow-up period. LLLT can be applied simultaneously with conventional therapy especially in patients who do not respond to conventional treatment or suffer from recalcitrant lesions.

\section{Ethical Considerations}

All subjects gave an informed consent to join this study. The study has been approved by the skin Research Center, Shahid Beheshti University of Medical Sciences, Tehran, Iran.

\section{Conflict of Interests \\ None.}

\section{References}

1. Scully C, Challacombe SJ. Pemphigus vulgaris: update on etiopathogenesis, oral manifestations, and management. Crit Rev Oral Biol Med. 2002;13(5):397-408.

2. Pick RM, Pogrel MA, Loh HS. Clinical application of CO2 laser. In: Miserendino LJ, Pick RM, eds. Lasers in Dentistry. Chicago: Quintessence; 1995:145-160.

3. Bhardwaj A, Joshi M, Sharma D. Management of recalcitrant oral pemphigus vulgaris with $\mathrm{CO}(2)$ laser - Report of two cases. J Indian Soc Periodontol. 2010;14(2):132-135. doi:10.4103/0972-124x.70835.

4. Karu T. Photobiology of low-power laser effects. Health Phys. 1989;56(5):691-704.

5. Litscher G. Integrative laser medicine and hightech acupuncture at the medical university of graz, austria, europe. Evid Based Complement Alternat Med. 2012;2012:103109. doi:10.1155/2012/103109.

6. Hopkins JT, McLoda TA, Seegmiller JG, David Baxter G. Low-level laser therapy facilitates superficial wound healing in humans: a triple-blind, sham-controlled study. $J$ Athl Train. 2004;39(3):223-229.

7. Minicucci EM, Miot HA, Barraviera SR, Almeida-Lopes L. Low-level laser therapy on the treatment of oral and cutaneous pemphigus vulgaris: case report. Lasers Med Sci. 2012;27(5):1103-1106. doi:10.1007/s10103-012-1101-8.

8. Shimizu T, Takebayashi T, Sato Y, et al. Grading criteria for disease severity by pemphigus disease area index. J Dermatol. 2014;41(11):969-973. doi:10.1111/13468138.12649.

9. Busnardo VL, Biondo-Simoes ML. [Effects of low-level helium-neon laser on induced wound healing in rats]. Rev Bras Fisioter. 2010;14(1):45-51.

10. Maiya AG, Kumar P, Nayak S. Photo-stimulatory effect of low energy helium-neon laser irradiation on excisional diabetic wound healing dynamics in Wistar rats. Indian
J Dermatol. 2009;54(4):323-329. doi:10.4103/00195154.57606

11. Castano AP, Dai T, Yaroslavsky I, et al. Low-level laser therapy for zymosan-induced arthritis in rats: importance of illumination time. Lasers Surg Med. 2007;39(6):543-550. doi:10.1002/lsm.20516.

12. Landau Z, Schattner A. Topical hyperbaric oxygen and low energy laser therapy for chronic diabetic foot ulcers resistant to conventional treatment. Yale J Biol Med. 2001;74(2):95-100.

13. Izikson L, Nelson JS, Anderson RR. Treatment of hypertrophic and resistant port wine stains with a 755 nm laser: a case series of 20 patients. Lasers Surg Med. 2009;41(6):427-432. doi:10.1002/lsm.20793.

14. Akyol UK, Gungormus M. Effect of biostimulation on healing of bone defects in diabetic rats. Photomed Laser Surg. 2010;28(3):411-416. doi:10.1089/pho.2008.2478.

15. Rezende SB, Ribeiro MS, Nunez SC, Garcia VG, Maldonado EP. Effects of a single near-infrared laser treatment on cutaneous wound healing: biometrical and histological study in rats. J Photochem Photobiol B. 2007;87(3):145-153. doi:10.1016/j.jphotobiol.2007.02.005.

16. Aleksic V, Aoki A, Iwasaki K, et al. Low-level Er:YAG laser irradiation enhances osteoblast proliferation through activation of MAPK/ERK. Lasers Med Sci. 2010;25(4):559569. doi:10.1007/s10103-010-0761-5.

17. Gaida K, Koller R, Isler C, et al. Low Level Laser Therapy-a conservative approach to the burn scar? Burns. 2004;30(4):362-367. doi:10.1016/j.burns.2003.12.012.

18. Gal P, Vidinsky B, Toporcer T, et al. Histological assessment of the effect of laser irradiation on skin wound healing in rats. Photomed Laser Surg. 2006;24(4):480-488. doi:10.1089/ pho.2006.24.480.

19. Lucas C, Stanborough RW, Freeman CL, De Haan RJ. Efficacy of low-level laser therapy on wound healing in human subjects: a systematic review. Lasers Med Sci. 2000;15(2):84-93.

20. Posten W, Wrone DA, Dover JS, Arndt KA, Silapunt S, Alam M. Low-level laser therapy for wound healing: mechanism and efficacy. Dermatol Surg. 2005;31(3):334-340.

21. Sobanko JF, Alster TS. Efficacy of low-level laser therapy for chronic cutaneous ulceration in humans: a review and discussion. Dermatol Surg. 2008;34(8):991-1000. doi:10.1111/j.1524-4725.2008.34197.x.

22. Schindl M, Kerschan K, Schindl A, Schön H, Heinzl $\mathrm{H}$, Schindl L. Induction of complete wound healing in recalcitrant ulcers by low-intensity laser irradiation depends on ulcer cause and size. Photodermatol Photoimmunol Photomed. 1999;15(1):18-21.

23. Pavlic V, Aleksic VV, Zubovic N, Veselinovic V. Pemphigus vulgaris and laser therapy: crucial role of dentists. Med Pregl. 2014;67(1-2):38-42.

24. Zand N, Mansouri P, Ataie-Fashtami L, Fateh M, Esmaeeli $\mathrm{GH}$, Alinaghizadeh M. Relieving pain in painful oral lesions of pemphigus vulgaris by a single session, nonablative $10600 \mathrm{~nm} \mathrm{CO} 2$ laser irradiation. The 29th Annual Conference of the American Society for Lasers in surgery and medicine. Harbor: American Society for Lasers; 2009:67-68 